УДК 616.89+159.9:616

DOI: 10.33184/NShvb-2021-11-22.6

Григорьева Мария Александровна

магистрант факультета психологии Башкирского государственного университета

Научный руководитель - Политика О. И.

\title{
НАРУШЕНИЯ КОГНИТИВНЫХ ПРОЦЕССОВ И СОЦИАЛЬНОГО ПОЗНАНИЯ У БОЛЬНЫХ ШИЗОФРЕНИЕЙ
}

Аннотация. $B$ данной статье рассматривается проблема расстройств когнитивных прочессов у больных шизофренией, нарушения социального интеллекта, социального познания и функиионирования при наличии у пациентов данного заболевания.

Ключевые слова: сочиальный интеллект, сочиальное познание, иизофрения.

Актуальность вопроса, касающегося комплекса расстройств познавательной области длилась в течение всего двадцатого века и, что примечательно, интерпретация когнитивной недостаточности поэтапно претерпевала изменения, начиная от ее рассматривания в качестве последствия болезни, заканчивая трактовкой в виде возможного фактора болезни. Детальное изучение поискового процесса искажений познавательных процессов у пациентов с наличием шизофрении способствует рассуждать о важнейшем вкладе в обозначенную сферу исследовательских работ и российских и западных авторов. Так, данное изучение, которое находится под сопровождением концептуального понимания примененных авторами моделей, освещается в рамках отечественных литературных источников [1, с. 216].

Главным предметом исследования являлась дисфункция когнитивных процессов у больных шизофренией, однако, зачастую ученые склонялись к исследованию общей картины нарушений, к примеру, 
селективности структуры психических процессов пациентов с шизофренией, нехватки разнообразия разновидностей памяти [4, с. 87].

Результатом исследований, продолжающихся долгие годы, оказалось понятие «нейрокогнитивного дефицита», которое было выдвинуто в конце двадцатого века, зачастую имеющее связь с комплексом негативных симптомов при наличии шизофрении [6, с. 229]. Высокий уровень повторяемости и эксплицитности выявляемых нарушений в когнитивной сфере и, их важность в рамках социальной деятельности пациентов, предоставили возможность рассуждать о них в качестве третьего основного раздела симптоматики шизофрении - на одном уровне с позитивной и негативной клинической симптоматикой, в дополнение к этому, они поспособствовали установлению осознания шизофрении в качестве болезни из раздела нейрокогнитивного диапазона.

Изначально источником незначительных искажений нейропсихологического спектра считался именно процесс болезни, и данная позиция была переведена в теоретическое предположение о таком свойстве, как нейротоксичность шизофрении [3, с. 54].

Между нейрокогнитивной недостаточностью и навыком пациентов проявлять свою деятельность в социуме были выявлены значимые связи. Несмотря на это, на протяжении возрастания количества исследовательских работ, были выявлены масштабные показатели нейрокогнитивной недостаточности у больных шизофренией в первый раз [2, с. 96]. Также выявилась связь нейрокогнитивной недостаточности с комплексом других нарушений, благодаря чему можно было интерпретировать набор неврологических и нейропсихологических симптомов в виде признаков шизофрении, а также осветить проблему о возможном явлении этой недостаточности в качестве центрального клинического признака шизофрении [7, с. 312].

Важнейшими стали факты, выявленные среди череды проведенных исследований, о том, что у пациентов, которым присущ высокий риск прогрессирования шизофрении свойственны результаты, которые были выявлены у людей с уже установленным диагнозом, а также о похожем наборе неврологических нарушений, хоть и меньшей выраженности, свидетельствуют показания близких членов семьи пациентов с наличием шизофрении, которым не свойственны психотические расстройства $[5$, с. $112]$.

В настоящий момент времени, утверждение о смягченных неврологических симптомах, считающихся генетическим показателем 
возможного прогрессирования шизофрении, официально общепризнанно $[6$, с. 243]; однако возникает информация о схожих отклонениях пациентов с рядом аффективных расстройств. Заинтересованность ученых в области нейропсихологических нарушений у больных шизофренией остается устойчивой, несмотря на существующую гипотезу о снижении исполнительных функций пациентов с наличием шизофрении и признающую расстройства лобных участков головного мозга (в особенности при наличии такой формы шизофрении, как «негативная»), а также обладающая таким статусом, как «нейропсихологическая парадигма», предоставляет место другим существующим теориям.

Среди заключительных, имеются догадки, содержащие в себе структурно-функциональный диссонанс в качестве причины нарушения течения психической деятельности у больных шизофренией [7, с. 321].

Стимулом продолжения исследовательских работ в сфере познавательных дисфункций при наличии шизофрении, считаются как новинки инструментальных преимуществ нынешней нейронауки, так и эволюция психологии когнитивного плана. К примеру, было осуществлено описание особого когнитивного стиля, свойственного больным шизофренией, выражающегося в дефиците медлительности и поэтапности в процессе воспроизведения когнитивных механизмов, вместо чего выдвигались преждевременные выводы.

Этот вид характеризуется дефицитом оперативного вида памяти, который не предоставляет возможности долго хранить и модифицировать информационный поток, а итогом данных ложных предположений, ученые предполагают прогрессирование бредовых установок и ложных рассуждений [1, с. 290].

В последнее время, различные исследователи, в виде фокусирования на эмпирическом методе исследования, выявляют дисфункции эксплицитного, имплицитного, ассоциативного, и автобиографического видов памяти, проводят анализ имеющихся данных в рамках теорий о возникновении и развития шизофрении и иных шизотипических расстройств индивида, вероятности применения имеющейся информации в целях предупреждения заболевания и проведения психотерапевтических работ у больных шизофренией.

Несмотря на это, набор вышеперечисленных когнитивных, а также нейропсихологических нарушений, не может полноценно отразить своеобразие такого заболевания, как шизофрения, которое было отмечено благодаря Э. Блейлеру и нашедшее зеркальность в рамках идеи об 
аутистическом мышлении. Следовательно, по этой причине, стало происходить поэтапное смещение фокуса на новый предмет изучения комплекс нарушений процессов познания другого вида, имеющих связь с познаванием и осознанием иной личности, взаимоотношений между индивидами, сложноорганизованных обстоятельств социального характера.

Количество трудов, которые были посвящены отклонениям в сфере социальных когниций, куда входит социальное познание и социальное поведение у пациентов с наличием шизофрении и смежных с этим заболеванием болезней, возрастает все больше с каждым годом.

Стоит отметить, что деятельность в обозначенной сфере считаются достаточно трудными, ибо в наличии имеется множество различий между социальными и несоциальными стимулами, рассматривая их с точки зрения ученых. Стимулы социума, в основном, наделены системой контекстуальных признаков, имеющих связь с воздействием таких сфер жизни, как культура, субъективный жизненный опыт, индивидуальная значимость для индивида, из-за этого возникают трудности в процессе унификации в качестве предоставляемого материала [9, с. 87].

Стимулы социума зачастую наделены двусмысленностью, отсутствием конкретики и четкости, а что касается пациентов с установленным клиническим диагнозом, они воспринимают их в качестве угрозы для своей жизни.

Помимо этого, данная разновидность стимулов обладает ярко выраженными искажениями под эмоциональным аффектом и аффективной нагруженности, значимость и воздействие которых тяжело, но очень важно оценивать с объективной точки зрения. Также, важно помнить о взаимосвязи между социальными когнициями речевыми механизмами, семантическим обрамлением накопленного опыта, из-за чего речевые нарушения могут оказывать воздействие на продуктивность реакций на стимулы и становится трудно сглаживать данные воздействия. Процесс восприятия стимулов социума, куда входят и мимические проявления окружающих, их взгляды, голосовые интонации, открытые поведенческие реакции, намеки, истинность намерений и пр. запрашивают полимодальность восприятия, соотношение поступающих данных с сохраненными воспоминаниями и комплексом впечатлений об индивидах в целом, а также об определенном индивиде, о явных и неявных для него выражениях эмоционального спектра. 
Бесспорно, что в данном случае механизмы восприятия имеют тесную связь с процессами памяти, мышления, и то, что существует необходимость другого уровня управления собственными состояниями и итогами деятельности - благодаря высокому уровню допущения возможной ошибки (к примеру, умение предсказывать последующее направление волана будет даваться проще, чем предсказывание последующих поступков в трудных социальных обстоятельствах, пусть даже очень хорошего знакомого).

Главное место занимает память и ее дисфункции, что обусловлено одновременным возрастанием заинтересованности в рамках психологии по отношению к пониманию социума и собственной реализации в нем, благодаря чему прослеживается постоянная работа над автобиографическим видом памяти, в качестве обозначения участков памяти индивида как отдельной личности, имеющей непосредственное отношение к познанию социума.

В случае же с субъективной потребностью воспринимать группы индивидов и их взаимоотношения, а не отдельную личность, то данная цель представляется наиболее трудновыполнимой и для индивида, который воспринимает окружающих людей, и для самих исследователей данного вида восприятия.

Но несмотря на это, исследования дисфункций познания социума, имеющееся у пациентов с шизофренией до сих пор, с высокой частотой реализуются в различных странах, базируясь на идеях концепции о социальном интеллекте, как в рамках психологии общего плана, социального и когнитивного, а также базируясь на трудах в сфере психокоррекционного и психосоциального содействия пациентам с данным диагнозом [8, с. 187]; при этом, заключительные из перечисленных, являются доказательством вероятного воздействия на дисфункции познания социума и поведенческие проявления, достигая таким образом, оптимизации жизнедеятельности пациентов в социуме, что также питает заинтересованность ученых.

Необходимо подчеркнуть, что дисфункции познания социума при наличии шизофрении, изначально интерпретируемые в качестве одной из сторон всеобщей нехватки навыков познания, начали трактовать в виде автономного типа дисфункций, представляющего особую важность для развития шизофрении [10, с. 89$]$. 


\section{Список использованных источников}

1. Клиническая психология: учебник / под ред. А.Б. Холмогоровой. - М.: Издательский центр Академия, 2012. Т. 2. - 432 с.

2. Лоскутова В.А. Социальные когнитивные функции при шизофрении и способы терапевтического воздействия // Социальная и клиническая психиатрия. 2009. Т. 19(4). С. 92-104.

3. Хломов Д.Н. Особенности восприятия межличностных взаимодействий больными шизофренией: дис. канд. психол. наук. - М., 1984. - 177 c.

4. Критская В.П., Мелешко Т.К., Поляков Ю.Ф. Патология психической деятельности при шизофрении: мотивация, общение, познание. - М.: Медицина, 1991. - 256 с.

5. Курек Н.С. Психологическое исследование когнитивного аспекта эмоциональных процессов у больных шизофренией // Журнал невр. и психиатр. 1988. № 7. С. 109-113.

6. Блейлер Э. Руководство по психиатрии. - Берлин: Изд-во «Врачъ», 1920. - 542 с.

7. Сергиенко Е.А., Лебедева Е.И., Прусакова О.А. Модель психического как основа становления понимания себя и другого в онтогенезе человека. - М.: Изд-во «Институт психологии РАН», 2009. $415 \mathrm{c}$.

8. Гурович И.Я., Шмуклер А.Б., Сторожакова Я.А. Психосоциальная терапия и психосоциальная реабилитация в психиатрии. - М: Медпрактика. 2004. - 492 с.

9. Кузин Ю.А. Исследование атрибуции при расстройствах шизофренического спектра // Социальная и клиническая психиатрия. 2014. T. 24(2). C. 99-106.

10. Шмуклер А.Б. Структурно-функциональная

рассогласованность различных отделов головного мозга при шизофрении: роль интегративной перцепции // Социальная и клиническая психиатрия. 2010.T. 20(3). C. 86-95.

(C) Григорьева М. А. 2021 